\title{
THE CONNECTION OF SMART CITIES APPROACH AND SOCIAL INNOVATION
}

\author{
Dóra Szendi \\ assistant professor, University of Miskolc, Institute of World and Regional Economics \\ 3515 Miskolc, Miskolc-Egyetemváros, e-mail: regszdor@uni-miskolc.hu
}

\begin{abstract}
The enhancing globalization raises new challenges for the cities, like the increasing number of urban population, the rising environmental problems, or the overcrowding of some cities. Nowadays with the widespread of intelligent technologies, more and more cities are creating strategies for making themselves more innovative, and smart. That is why the inequalities among different cities are also rising, as some of them cannot adapt these challenges and turns to a relatively peripheral situation. In their case social innovation can be an adequate solution for solving the problems in a bottom-up way, and foster their development. The aim of this research is to analyse the connection of smart cities with the idea of social innovation, as they both have some similar characteristics.
\end{abstract}

Keywords: smart city, social innovation, metropolitan regions, penta-helix.

\section{Introduction}

Nowadays with the widespread dispersion of the industry 4.0 and the globalization new challenges are emerging in the world economy. The countries, regions and even the cities have to adapt the rapidly changing conditions occurring from that process. That is why the notion of smart cities and social innovation have gained increased attention in the literature. Nowadays, smart urban development and the use of smart / intelligent technologies is gaining increasing importance in many parts of the world, on almost every continent. The smart city is a settlement, which integrates all infrastructure elements to optimize resources and increase competitiveness while improving the quality of life of the population. In this context, the early definitions were mainly focusing on technology and innovation (e.g. [1] or [2]), but nowadays also there are some soft elements among the approaches. At the same time, these applications cannot be applied in every region/city, because some problems of the disadvantaged, peripheral regions cannot be solved by classical technological innovations due to low innovation potential (absorption capacity). Therefore, new or novel solutions are needed that provide creative answers to these problems ([3], [4], [5]) and can serve as effective innovation through bottom-up initiatives. In this approach, the social innovations can be a good solution for enhancing the catch-up of these territories.

The basic aim of this paper is to examine the connection of smart cities and social innovation, what kind of interconnections can be found among the notions, and from which aspect are they similar to each other. 


\section{Theoretical background}

\subsection{The notion of smart cities}

The concept of the smart city originally appeared in the literature in the 1980s and '90s, focusing on the role of information and communication technologies (ICT). After that time, many other aspects like resilience, the sustainable side or the social side of interactions extended the notion. Nowadays we can group the different aspects quite good, but there is no agreed-on definition in the literature, as every city has its own unique character, historical development, and future dynamics, that is why the adaptation of the concept is different. The technocratic concepts emphasize that a smart city integrates its resources and infrastructural elements to serve there inhabitants' needs better (e.g. [1]), and they connect the cities' physical, IT, social and business infrastructure to enhance the collective intelligence of their citizens. Other approaches stress that through the increased significance of the knowledge-societies the innovation and knowledge will be the most relevant factor by creating smart environments. Based on Hollands [6] or Komninos [7] a smart city can be characterized by an extremely high share of knowledge and innovation (because of a creative population and the activity of institutions).

Moreover Schaffers [8] states that smart cities initiatives try to improve urban performance by using data, information and information technologies (ICT) to provide more efficient services to citizens, to monitor and optimize existing infrastructure, to increase collaboration among different economic actors, and to encourage innovative business models both the private and public sectors. So besides the topdown types of interactions it is also important to increase the level of bottom-up initiatives and encourage their participation by smart cities. That is why in my definition, the smart city is a complex notion. It means a city, which uses innovative strategies and solutions to create better living conditions for the citizens, by the efficient use of the citizens' creativity and knowledge basis [9].

\subsection{Defining social innovation}

As territorial disparities increase, there has been a growing need to measure inequalities, and recognizing the importance of social innovation in the potential decrease of territorial disparities, many researchers have turned to a novel direction in the study of innovation. More and more researchers have addressed the issue, several of whom (e.g. [4]) stressed that in the case of peripheral areas, in addition to local or national government actions, bottom-up initiatives are needed to address the problems. In this approach, social innovation emerged as a new form of meeting the social needs.

The social innovation, compared to the previous one, also doesn't have a commonly agreed definition, as the content can be various based on the geographical location, policy and other areaspecific parameters.

One of the most complex and shortest definitions of social innovation is attributed to Mulgan et al. [10] who stated that it is a new idea, which meets an until now unmet social need. Rehfeld et al. [11] also emphasized the novel nature of social innovation and that social innovation can also help to encourage collaboration between different groups in society. The latter can also help to reduce social disparities and meet needs that cannot be met by the market. The reduction of social differences has also appeared in the works of other authors, e.g. Moulaert et al. [3] considered the focus on balancing economic differences to be a fundamental feature of social innovation ([12], p. 2). 


\section{Connection of smart cities and social innovation}

Based on the above, common character of both social innovation and smart cities is that there is a lack of clear, unique definition, and depending on the socio-economic context, their content may be different. In the most complex definitions of smart cities, the human factors are gaining increased importance, and besides knowledge and innovation factors, some soft elements, like quality of education, quality of life appear [13]. So these two theories show quite significant interconnections.

In the early 1900's, Ebenezer Howard (1902) dreamed of the city of the future in his study Garden Cities of Tomorrow. His goal was to combine the benefits of rural and urban life style/ existence in the city while eliminating their disadvantages. This can be considered as the very first step in the approach of cities that takes into account the aspects of their inhabitants. Rios (2008) has emphasized that the cities that give inspiration, share culture, knowledge, and life, and cities that motivate its inhabitants to create and flourish in their own lives can be considered as a smart settlement. Many of the studies put increased attention to the bottom-up character of smart city initiatives in Europe which is a critical factor also in case of the social innovation.

With the even accelerating industry 4.0 digital technologies and technological innovations are considered as the driving force of city level developments [14], but in some territories with relatively low technological innovation/FDI absorption capacity the bottom-up initiatives and social innovation could foster the development.

In both cases there is a need for strong relationship of different stakeholders to realize the objectives, and in this way organization, companies, institutions, civil and NGOs, urban and local authorities are working together to achieve goals [15] and enhance the quality of life of the inhabitants. As an effect of the initiatives, the projects and solutions can be the results of technological or social innovations.

The collaboration of the different stakeholders vary from city to city, there is not a common framework of that, but usually the main shames are the same as by the social innovation framework conditions. There are three relevant approaches we have to mention in this connection, from which all of them can be effective by different conditions. The oldest, and probably the most used one is the socalled triple-helix model, which builds on the cooperation of the public, private and academic field to generate projects in a mainly top-down perspective. Compared to this, the quadruple-helix integrates also the civic society and that is why it can react more flexible on the problems of society and creates an institutionalised bottom-up framework for solving the problems. Nowadays with the widespread flow of social innovation ideas, and initiatives, a new framework was built up for generating social innovation ideas, and because of its bottom-up character it can serve also the smart city initiatives. This is the pentahelix model which contains also the participation of the social entrepreneurs and activists to its proactive model [16]. In the case of smart cities and social innovation, the penta-helix could be one of the most adequate solution for generating projects, and to solve the problems of the society more effectively than the market. The different framework models are summarized in the next Figure 1.

\section{Analysis and results}

My former analysis [9] has proved, that based on the complex smart city index, Copenhagen was the best performing city/functional urban area among the analyzed ones, which was followed by Stockholm and Luxemburg. The highest index values have capital cities from the Northern and Western member states, while the lowest values are identifiable in the Eastern and Southern periphery. So the complex inequalities of the EU (western-eastern and northern-southern) can be verified also by the smart index. 


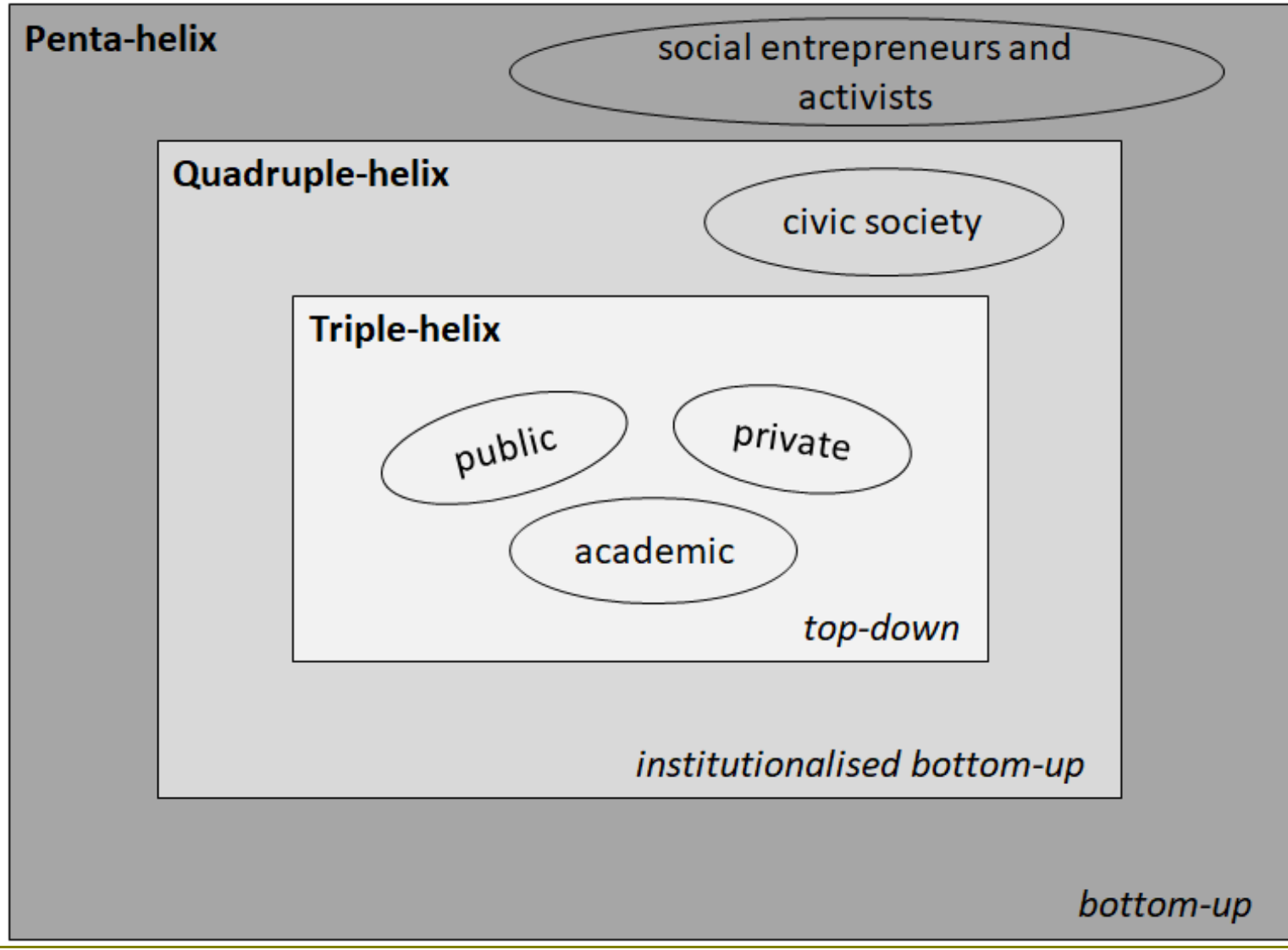

Figure 1. Different framework models of social innovation and smart cities (Source: own compilation based on Calzada, 2020).

In this recent research I have also examined the so-called functional urban areas based on their technological innovation performance, because I had the assumption that in the regions where the traditional forms of innovation are absent or its activity is not good enough, the solution for fulfilling the society's needs can be found in social innovation.

In the case of the metropolitan areas, I have checked the differences in the distribution of the patent applications. I have checked the dispersion for 2015 based on the dates of the Eurostat Metropolitan region database (Figure 2).

From the Figure 2, I can state that the pattern of the patent applications show quite clear westerneastern and northern-southern differences in Europe. The hot spots are concentrating in the northern and north-western part of the EU, mainly in Belgium, northern Germany and Denmark. The cold spots can be found, in Poland, Romania and Bulgaria.

The most intensive patent activity (biggest hot spots) can be verified in the Benelux states (Belgium, the Netherlands, and Luxemburg), in southern and south western Germany (in the area of Bavaria, Baden-Württemberg and the Ruhr area), and in northern Italy (in the territory of the Milan - Turin Genova triangle).

So the territories, where the lowest patent activity and smart initiatives can be observed, are there in the southern and eastern periphery of the European continent. 


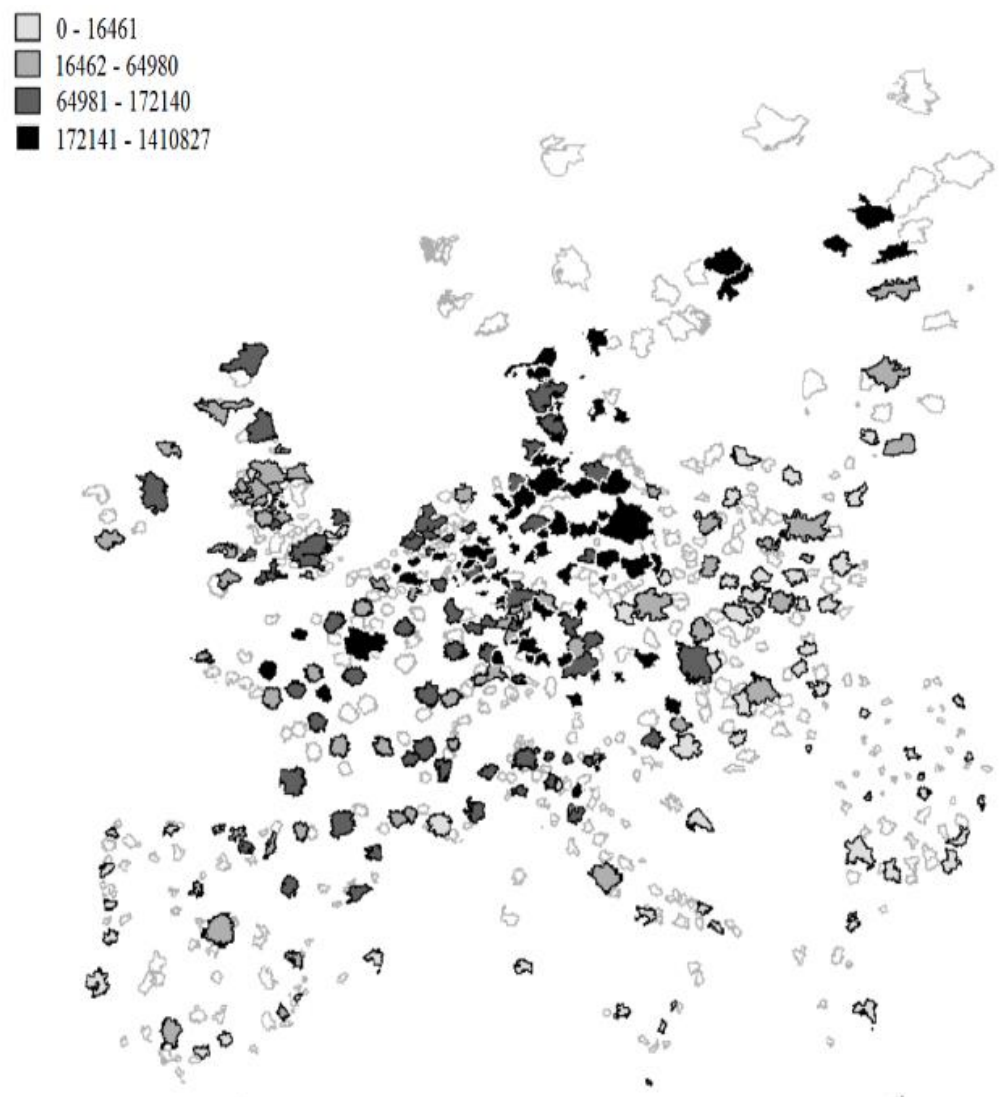

Figure 2. Patterns of the patent applications across the metro regions (2015) (Source: own compilation based on Eurostat data)

\section{Summary}

In this recent research I have examined the connection of smart cities and social innovation and have observed that the two notions are generally not too far from each other, as there framework conditions can be very similar at some points. In both cases there is a need for strong relationship of different stakeholders to realize the objectives, and to achieve it nowadays the penta-helix model can be an adequate solution, which builds on the cooperation of public, private sector, academic field, civic society and the social entrepreneurs and activists. With this model, also the catch-up of peripheries could be fostered and there convergence chances could increase.

\section{Acknowledgements}

The research reported here was carried out as part of the EFOP-3.6.1-16-2016-00011 "Younger and Renewing University - Innovative Knowledge City - Institutional development of the University of Miskolc aiming at intelligent specialization" project implemented in the framework of the Szechenyi 2020 program. The realization of this project is supported by the European Union, co-financed by the European Social Fund. 


\section{References}

[1] Hall, R. E.: The vision of a smart city, 2000 In Proceedings of the 2nd International Life Extension Technology Workshop, Paris, France.

[2] Harrison, C., Eckman, B., Hamilton, R., Hartswick, P., Kalagnanam, J., Paraszczak, J., Williams, P.: Foundations for smarter cities, IBM Journal of Research and Development, 54 (4), (2010) pp. 350-365. https://doi.org/10.1147/JRD.2010.2048257

[3] Moulaert, F., Maccallum, D., Mehmood, A., Hamdouch, A.: The international handbook on social innovation: collective action, social learning and transdisciplinary research, Cheltenham: Edward Elgar, 2014. https://doi.org/10.4337/9781849809993

[4] Benedek, J., Kocziszky, Gy., Veresné Somosi, M., Balaton, K.: Generating and measuring regional social innovation, Theory Methodology Practice, 12 (special issue), (2016) pp. 14-25. https://doi.org/10.18096/TMP.2016.02.02

[5] Süveges, G.: The relationship between aims, methods and their financial aspects in the case of social innovations in the field of district heating, Oradea Journal of Business and Economics 2501-1596 2501-3599 IV. Special Issue, (2019) pp. 29-38.

https://doi.org/10.47535/19910jbe065

[6] Hollands, G. R.: Will there all smart city please stand up? City, 12 (3), (2008) pp. 303-320. https://doi.org/10.1080/13604810802479126

[7] Komninos, N.: Intelligent cities: Variable geometries of spatial intelligence, Intelligent Buildings International, 3 (3), (2011) pp. 172-188. https://doi.org/10.1080/17508975.2011.579339

[8] Schaffers, H., Komninos, N., Pallot, M., Trousse, B., Nilsson, M., Oliveira, A.: Smart cities and the future internet: Towards cooperation frameworks for open innovation, Future Internet Assembly, LNCS 6656, 2011. https://doi.org/10.1007/978-3-642-20898-0_31

[9] Szendi, D.: Measuring the smart cities' performance in the capital cities of the EU, In: University of Ho Chi Minh City (ed.) Proceedings of the International Conference, 2019 Special mechanism and policy for the development of Ho Chi Minh City from the legal perspective; Ho Chi Minh City, Vietnam, pp. 87-120.

[10] Mulgan, G.: Social innovation; What it is, why it matters and how can be accelerated, Skoll Centre for Social entrepreneurship, The Young Foundation, Oxford University, UK., 2007.

[11] Rehfeld, D., Terstriep, J., Welchhoff, J., Alijani, S.: Comparative report on social innovation framework, SIMPACT Working Paper, Germany, 2015.

[12] Nicholls, A., Murdock, A.: Social innovation. Blurring boundaries to reconfigure markets, Palgrave Macmillan, Houndmills, Basingstoke, UK., 2012.

[13] Bencardino, M., Greco, I.: Smart communities: Social innovation at the service of the smart cities, TeMA Journal of Land Use, Mobility and Environment, (2014) pp. 39-51.

[14] Kim, H. M., Sabri, S., Kent, A.: Smart cities as a platform for technological and social innovation in productivity, sustainability, and livability: A conceptual framework, Elsevier, 2021. https://doi.org/10.1016/B978-0-12-818886-6.00002-2

[15] Husar, M., Ondrejicka, V.: Social innovations in smart cities - Case of Poprad. Mobile Networks and Applications 24 (2019) pp. 2043-2049. https://doi.org/10.1007/s11036-018-01209-z

[16] Calzada, I.: Democratising smart cities? Penta-Helix Multistakeholder Social Innovation Framework, Smart Cities 2020, 3, (2020) pp. 1145-1173.

https://doi.org/10.3390/smartcities3040057 